\section{Manual para diagnóstico de administração de empresas}

Por Vitor Dias Pina, Evando V. de Barros, Savio Coube Bogado, Eddy F. Pontes Filho, Carlos Augusto S. Cunha e João Henrique F. Santos. 2. ed. São Paulo, Editora Atlas, 1972.

O manual em questão foi desenvolvido por esta equipe de pesquisadores segundo resultados obtidos através de anos de observações, análises e experimentações em numerosas empresas industriais do país, promovidas pela Universidade Federal Fluminense.

Além da autoridade técnica da equipe, deve ser ressaltada a experiência pessoal de seus componentes em diversas atividades docentes, de consultorias e industriais.

Durante 10 anos, desde 1959, - GEPI - Grupo de Estudo de Produtividade Industrial - de cujo corpo técnico a equipe faz parte, acompanhou com atenção a atuação dos empresários nacionais, constatando que muitos dos dirigentes e técnicos não têm um conhecimento razoavelmente preciso da situação de suas empresas.

Os autores do trabalho, como componentes do GEPI, procuraram em diversas entidades brasileiras documentos que se apresentassem como uma metodologia para diagnóstico de administração de empresas, não encontrando, porém, material representativo das necessidades e condições da indústria brasileira. Pensaram então os autores em suprir essa lacuna, elaborando uma criação teórica da metodologia a partir de documentos sobre organização e administração de empresas com ênfase nas condições nacionais. Foram programados e realizados testes experimentais.

O corpo técnico teve a oportunidade de realizar este trabalho junto à região geoeconômica do Grande Rio, incorrendo, portanto, na elaboração do Manual de organização e administração da indústria têxtil - nos ex-Estados do Rio de Janeiro e Guanabara, publicado em 2000 exemplares, com razoável repercussão junto aos órgãos governamentais e aos empresários nacionais. Da pesquisa e experiências complementares surgiu o Manual para diagnóstico de administração de empresas, objetivando apresentar o método de diagnóstico de forma acessivel, não discorrendo sobre as técnicas e problemas de administração de empresas. Partiram os autores do princípio de que os que se interessarem já deverão possuir conhecimentos necessários sobre 0 assunto. No final de cada área de estudo são apresentadas bibliografias de livros selecionados, que poderão servir de orientação para estudos complementares. O leitor encontrará, não os diversos aspectos do diagnóstico, mas indicações objetivas e orientações que não esgotam o assunto, mas esclarecem suficientemente.

São abordadas inicialmente, noções gerais sobre o diagnóstico, destacando seus objetivos e vantagens e informando sobre os tipos de empresa em que pode ser aplicado e sobre os requisitos necessários às pessoas encarregadas deste tipo de trabalho.
Logo a seguir os autores apresentam a metodologia do diagnóstico, expondo o método segundo suas quatro fases: preparação, levantamento com todos os tipos de questionários aplicáveis à administração geral, administração de vendas, da produção - análise de materiais, de pessoal e financeira, (formas e implicações), quadro geral da empresa e relatório final.

Após os questionários de cada área, é apresentado um exemplo de aplicação.

O objetivo-base é orientar executivos e administradores quanto à forma de contato com os numerosos problemas existentes em sua organização, como proceder à apuração e como se posicionar corretamente na função de análise, a fim de que possam ser corrigidos procedimentos administrativos, tornando-os mais eficientes.

Trata-se realmente de um manual e pode ser de grande utilidade no tratamento de aspectos especificos (unidades dentro de uma organização) ou gerais (visão sistêmica).

Luís Cesar G. de Araújo 